\title{
Erratum
}

\section{Thermal and Au(I)-Catalyzed Intramolecular [4+2] Cycloaddition of Aryl- Substituted 1,6-Diynes for the Synthesis of Biaryl Compounds}

Takanori Shibata,* Ryo Fujiwara, Daisuke Takano Synlett 2005, 2062-2066.

In the original article the mechanism of the reaction given in Table 2 (incorrect original shown below) was misinterpreted as $\mathrm{Au}(\mathrm{I})$-catalyzed [4+2] cycloaddition. Further investigation, which was stimulated by Lian et al., ${ }^{1}$ revealed that it is a [3+2] cycloaddition that leads to the main product $\mathbf{3 a}$.

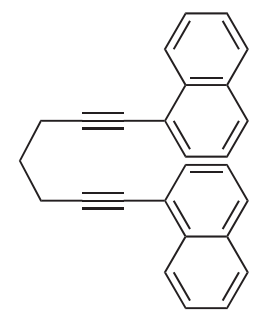

$1 \mathrm{a}$

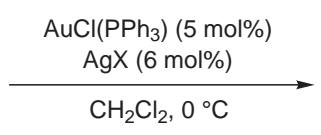

$\mathrm{CH}_{2} \mathrm{Cl}_{2}, 0^{\circ} \mathrm{C}$

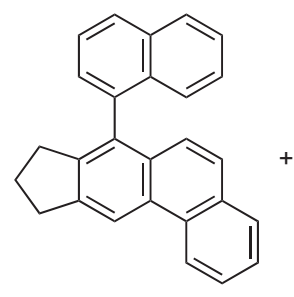

$2 \mathbf{a}$

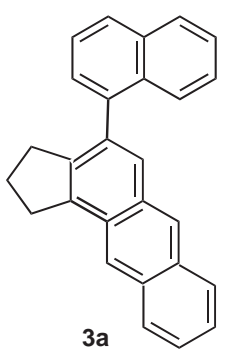

The structures of compounds $\mathbf{3 a}, \mathbf{d}, \mathbf{e}, \mathbf{i}-\mathbf{l}$, and $\mathbf{3 o} \mathbf{o}^{\prime} \mathbf{k}, \mathbf{l}\left[\mathrm{Z}=\mathrm{CH}_{2}, \mathrm{C}\left(\mathrm{CO}_{2} \mathrm{Et}\right)_{2}, \mathrm{NTs}\right]$ in Tables 2 and 3 were misinterpreted and the correct structures are shown below.<smiles>[Z]C1CC=C2C(=C(c3cccc4ccccc34)c3ccc4ccccc4c32)C1</smiles>

3a,d,e

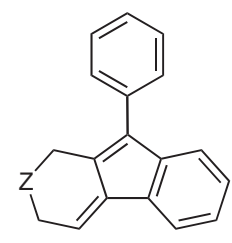

$3 \mathrm{i}, \mathrm{j}$<smiles>[Z]C1CC2=C(C1)c1ccccc1C2=C1CC=Cc2ccccc21</smiles>

$3 k, 1$

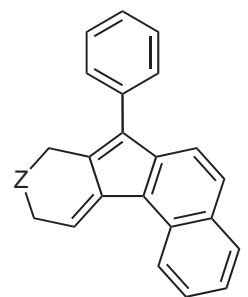

3'a,k,I

The structure of 3e $(Z=N T s)$ was ascertained by X-ray measurements (CCDC 618808).

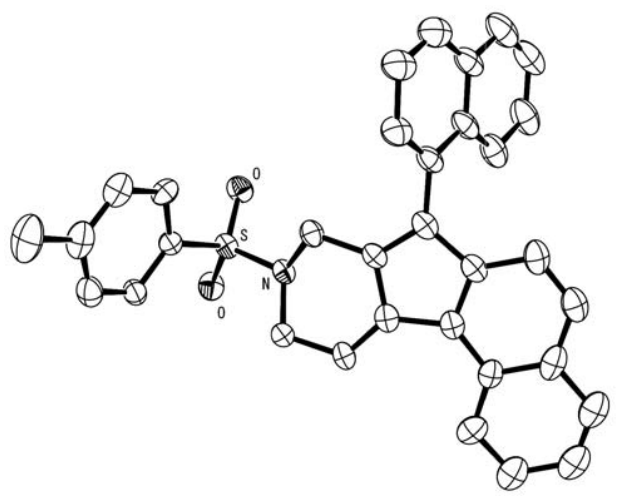

(1) Lian, J.-J.; Chen, P.-C.; Lin, Y.-P.; Ting, H.-C.; Liu, R.-S. J. Am. Chem. Soc. 2006, 128, 11372.

The authors apologize for these errors. 